\title{
Alberto Caeiro: poeta por natureza
}

\section{Marcio Roberto Pereira*}

E assim escrevo, querendo sentir a Natureza, nem sequer como um homem, Mas como quem sente a Natureza, e mais nada. E assim escrevo, ora bem, ora mal, Ora acertando com o que quero dizer, ora errando,

Caindo aqui, levantando-me acolá, Mas indo sempre no meu caminho como um cego teimoso.

Ainda assim, sou alguém. Sou o Descobridor da Natureza. Sou o Argonauta das sensações verdadeiras. Trago ao Universo um novo Universo Porque trago ao Universo ele-próprio. Alberto Caeiro, O guardador de rebanhos.

Resumo: Alberto Caeiro é considerado por Fernando Pessoa e seus demais heterônimos como o centro de todo um universo poético e filosófico. Assim sendo, ao definir O guardador de rebanhos como um ponto de "resolução" para as angústias do homem moderno e um enfrentamento do nada e do silêncio, por meio de uma poesia que integra o ser humano num contexto natural, Fernando Pessoa estabelece o apagamento de toda forma de sofrimento. Esse texto procura analisar as relações entre Caeiro e seus "discípulos" por meio de um ponto de convergência: as "Notas para a recordação do meu mestre Caeiro".

Palavras-chave: Poesia portuguesa. Alberto Caeiro. Fernando Pessoa.

\begin{abstract}
Alberto Caeiro is considered by Fernando Pessoa and his other heteronians as the center of an entire poetic and philosophical universe. Thus, by defining The keeper of herds as a point of "resolution" for the anguish of modern man and a face of nothingness and silence, through a poetry that integrates the human being in a natural context, Fernando Pessoa establishes the payment of all forms of suffering. This text seeks to analyze the relations between Caeiro and his "disciples" through a point of convergence: the "Notes for the remembrance of my master Caeiro".
\end{abstract}

Keywords: Portuguese poetry. Alberto Caeiro. Fernando Pessoa.

\footnotetext{
" É professor da Universidade Estadual Paulista (UNESP/Assis). Membro do BRASA - Brazilian Studies Association e da AIL - Associação Internacional de Lusitanistas. Vice-líder do Grupo de Pesquisa "Memória e Representação Literária". https://orcid.org/oooo-0003-4311-9629 / marciorpereira@uol.com.br
}

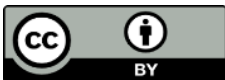




\begin{abstract}
Abstrakt: Alberto Caeiro wird von Fernando Pessoa und seinen anderen Heteronern als Zentrum eines ganzen poetischen und philosophischen Universums betrachtet. So, indem er das Werk Der Hüter der Herden als einen Punkt der "Auflösung" für die Angst des modernen Menschen und ein Gesicht des Nichts und der Stille definiert, durch eine Poesie, die den Menschen in einen natürlichen Kontext integriert, stellt Fernando Pessoa die Bezahlung aller Formen des Leidens fest. Dieser Text versucht, die Beziehungen zwischen Caeiro und seinen "Jüngern" durch einen Punkt der Konvergenz zu analysieren: die "Notizen für die Erinnerung an meinen Meister Caeiro".
\end{abstract}

Stichworte: Portugiesische Poesie. Alberto Caeiro. Fernando Pessoa.

Ao se considerar a heteronímia como um processo orgânico de consciência de si, observa-se que a obra de Fernando Pessoa (1888-1935) se constrói a partir de linhas de confluência que amplificam o conceito do "fazer literário" para um aspecto mais amplo de "viver o literário". Assim sendo, a criação de um universo de “personas literárias”, seja no plano crítico ou no literário, aproxima as diversas consciências artísticas de Fernando Pessoa.

Tais problematizações das consciências artísticas de Pessoa não se centralizam apenas em sua figura viva e de carne e osso, mas, muito comumente, em figuras heteronímicas que ganham independência e autoridade para mover-se livremente nesse universo orgânico e em constante expansão: "com uma tal falta de literatura, como há hoje, que pode um homem de génio fazer senão converter-se, ele só, em uma literatura?" (PESSOA, 1966, p. 145). A posição de Caeiro na constelação pessoana é tão importante a ponto de Fernando Pessoa, ao ser retratado por Álvaro de Campos, nas "Notas para a recordação do meu mestre Caeiro", ser equiparado a um ser ficcional como os próprios heterônimos:

Mais curioso é o caso do Fernando Pessoa, que não existe, propriamente falando. Este conheceu Caeiro um pouco antes de mim - em 8 de Março de 1914, segundo me disse. Nesse mês, Caeiro viera a Lisboa passar uma semana e foi então que o Fernando o conheceu. Ouviu ler o Guardador de Rebanhos. Foi para casa com febre, e escreveu, num só lance ou traço, a Chuva Oblíqua. A Chuva Oblíqua não se parece em nada com qualquer poema do meu mestre Caeiro, a não ser em certa rectilineadade do movimento rítmico. Mas o Fernando Pessoa era incapaz de arrancar aqueles extraordinários poemas do seu mundo interior se não tivesse conhecido Caeiro. Mas, momentos depois de conhecer Caeiro, sofreu o abalo espiritual que produziu esses poemas. Foi logo. Como tem uma sensibilidade excessivamente pronta, porque acompanhada de uma inteligência excessivamente pronta, o Fernando teve sem demora a reacção à Grande Vacina - a vacina contra a estupidez dos inteligentes. E o que 
há de mais admirável na obra do Fernando Pessoa é esse conjunto de seis poemas, essa Chuva Oblíqua. Sim, poderá haver ou vir a haver, coisas maiores na obra dele, mas mais originais nunca haverá, mais novas nunca haverá, e eu não sei portanto se as haverá maiores. E, mais, não haverá nada de mais realmente Fernando Pessoa, de mais intimamente Fernando Pessoa. Que coisa pode exprimir melhor a sensibilidade sempre intelectualizada, a atenção intensa e desatenta, a subtileza quente da análise fria de si mesmo, do que esses poemas-intersecções, onde o estado de alma é simultaneamente dois, onde o subjectivo e o objectivo, separados, se juntam, e ficam separados, onde o real e o irreal se confundem, para que fiquem bem distintos. Fernando Pessoa fez nesses poemas a verdadeira fotografia da própria alma. Num momento, num único momento, conseguiu ter a sua individualidade que não tivera antes nem poderá tornar a ter, porque a não tem. (LOPES, 1990, p. 369).

Nota-se, portanto, como as fronteiras da criação são tão tênues a ponto de, numa carta a Fernando Pessoa, em 8 de outubro de 1914, o poeta Mário de Sá-Carneiro comentar uma notícia de Alfredo Guisado: "O Guisado fala-me na carta que ontem me referi, dum poeta Caeiro, ou o que é, que diz mal da gente e encontrou entre galegos. Se calhar é mais um lepidóptero e provinciano!" (SÁ-CARNEIRO, 1979, p. 21).

Esse processo criativo que misturava ficção e realidade, ao envolver diversas formas de compreensão de um heterônimo, mostra como Alberto Caeiro é um ponto de convergência entre poetas e escritores reais e aqueles criados por Fernando Pessoa. Há uma ficcionalização da realidade e um caminho contrário que trata o real como uma ficção. Nesse sentido, o importante trabalho da Biblioteca Nacional de Portugal, ao organizar e divulgar o espólio de Fernando Pessoa, delineia a trajetória de Caeiro a partir da análise de seus papéis. Eis a cronologia dos poemas, organizada pela BNP, sob a coordenação de Ivo Castro", mostrando que o "Dia triunfal" pode ser, também, uma “invenção" de Fernando Pessoa:

Tabela 1: Índice de poemas de O guardador de rebanhos

\footnotetext{
1 "Dir-se-ia que Pessoa, escrevendo à distância de mais de vinte anos, recordava o caderno como o primeiro suporte em que os versos de Caeiro tiveram vida, precedidos pelo título. De facto, o título lá está, a meio da folha inicial do caderno. Mas a evidência do dossier genético diz-nos que a escrita dos poemas do Guardador tinha começado antes, nos rascunhos, e continuado depois, nas inúmeras emendas que o caderno foi acolhendo. Esta evidência só existe graças à preservação de todos os papéis anteriores e posteriores ao «dia triunfal» (à fé das datas, nenhum poema foi escrito em 8-3-1914). Deve ser atribuído a essa preservação um estatuto de deliberado acto autoral, que não fica abaixo dos gestos de escrita. O que nos faz concluir que Pessoa escreveu e contra-escreveu. Interrogado sobre a criação dos heterónimos, não declarou que a ideia foi surgindo aos poucos, como os papéis sugerem; mas conservou os papéis, para que contassem a sua história. E contou a Casais Monteiro a história de outra maneira." (CASTRO, 2006, p. 9).
} 


\begin{tabular}{|c|c|}
\hline 1914 Mar. 4 & O luar quando bate na relva $[67-38 \mathrm{av}]$ \\
\hline 1914 Mar. 7 & O Tejo é mais belo que o rio que corre pela minha aldeia [67-29av-29ar] \\
\hline 1914 Mar. 8 & Eu nunca guardei rebanhos, [145] \\
\hline 1914 Mar. 8 & Tudo que vejo está nítido como um girassol. [145] \\
\hline 1914 Mar. 11 & Às vezes, em dias de luz perfeita e exacta, [145] \\
\hline 1914 Mar. 11 & Às vezes, nos dias de luz perfeita e exacta [67-31r] \\
\hline 1914 Mar. 13 & O que nós vemos das coisas são as coisas... [67-3oav] \\
\hline 1914 Mar. 13 & O que nós vemos das coisas são as coisas. [145] \\
\hline 1914 Mar. 13 & As bolas de sabão que esta criança [67-3or] \\
\hline 1914 Mar. 13 & As bolas de sabão que esta criança [145] \\
\hline 1914 Maio 7 & Acordo de noite subitamente, [145] \\
\hline 1914 Maio 7 & Antes o voo da ave, que passa e não deixa rasto, [145] \\
\hline 1914 Maio 7 & Mas graças a Deus que há imperfeição no mundo [67-39r] \\
\hline 1914 Maio 7 & No entardecer dos dias de verão, às vezes, [67-39r] \\
\hline 1914 Maio 7 & No entardecer dos dias de verão, às vezes, [145] \\
\hline 1914 Maio 7 & Passa uma borboleta por diante de mim [145] \\
\hline 1914 Maio 7 & Passou a diligência pela estrada, e foi-se; [145] \\
\hline 1914 Maio 7 & Um renque de árvores lá longe, lá para a encosta. [145] \\
\hline 1914 Maio 7 & Voa uma borboleta por diante de mim [67-39r] \\
\hline 1914 Maio 10 & Deste modo ou daquele modo [67-10v e 9v] \\
\hline 1914 Jul. 6 & Quando eu não te tinha $[67-55 \mathrm{r}]$ \\
\hline 1914 Set. 17 & Passar a limpo a matéria $[57 \mathrm{~A}-57 \mathrm{~V}]$ \\
\hline 1915 Nov. 7 & A espantosa realidade das coisas $[67-53]$ \\
\hline 1915 Nov. 7 & Quando vier a primavera, $[67-51 v-52 r]$ \\
\hline 1915 Nov. 8 & Um dia de chuva é tão belo como um dia de sol. [67-54r] \\
\hline 1915 Nov. 8 & É noite. A noite é muito escura. Numa casa a uma grande distância [67-58r] \\
\hline 1915 Nov. 8 & Nunca sei como é que se pode achar um poente triste. [67-54r] \\
\hline 1915 Nov. 8 & Quando a erva crescer em cima da minha sepultura, [67-54v] \\
\hline 1915 Nov. 8 & Se, depois de eu morrer, quiserem escrever a minha biografia, [67-54r] \\
\hline 1916 Jan. 11 & Todas as teorias, todos os poemas $[58-2 \mathrm{v}]$ \\
\hline 1917 Maio 21 & Eu queria ter o tempo e o sossego suficientes $[58-45 \mathrm{v}]$ \\
\hline 1917 Maio 21 & Leram-me hoje S. Francisco de Assis. [58-45r] \\
\hline 1917 Maio 21 & Sempre que penso uma coisa, traio-a [58-45v] \\
\hline
\end{tabular}




\begin{tabular}{|c|c|}
\hline 1917 Out. 1 & $\begin{array}{l}\text { Assim como falham as palavras quando querem exprimir qualquer } \\
\text { pensamento, }[16 \mathrm{~A}-6 \mathrm{v}]\end{array}$ \\
\hline 1917 Out. 1 & Creio que irei morrer. [16A-7r] \\
\hline 1917 Out. 1 & A criança que pensa em fadas e acredita nas fadas [16A-7r] \\
\hline 1917 Out. 1 & De longe vejo passar no rio um navio... [16A-7r] \\
\hline 1917 Out. 1 & O espelho reflecte certo; não erra porque não pensa. [16A-6v] \\
\hline 1917 Out. 1 & Estas verdades não são perfeitas porque são ditas, [16A-6v] \\
\hline 1917 Out. 1 & Estou doente. Meus pensamentos começam a estar confusos. [16A-7v] \\
\hline 1917 Out. 1 & ....mas o Universo existe mesmo sem o Universo [16A-7v] \\
\hline 1917 Out. 1 & No dia brancamente nublado entristeço quase a medo [16A-6r] \\
\hline 1917 Out. 1 & A noite desce, o calor sossobra um pouco. [16A-7v] \\
\hline 1917 Out. 1 & Se o homem fosse, como deveria ser, [16A-6r] \\
\hline 1917 Out. 1 & O único mistério do Universo é o mais e não o menos. [16A-6r] \\
\hline 1917 Out. 1 & O Universo não é uma ideia minha, [16A-6v] \\
\hline 1917 Out. 24 & Seja o que for que esteja no centro do mundo, [67-59] \\
\hline 1918 Maio 29 & A água chia no púcaro que elevo à boca. [16A-9r] \\
\hline 1918 Maio 29 & Navio que partes para longe, $[16 \mathrm{~A}-8 \mathrm{r}]$ \\
\hline 1918 Maio 29 & O que ouviu os meus versos disse-me: Que tem isso de novo? [16A-9v] \\
\hline 1918 Maio 29 & Pouco a pouco o campo se alarga e se doura. [16A-9r] \\
\hline 1918 Maio 29 & Todas as opiniões que há sobre a Natureza [16A-8-9] \\
\hline 1918 Maio 29 & Última estrela a desaparecer antes do dia, [16A-9r] \\
\hline 1919 Abr. 12 & Ah, querem uma luz melhor que a do sol! [68-12] \\
\hline 1919 Abr. 12 & Uma gargalhada de rapariga soa do ar da estrada. [67-49v] \\
\hline 1919 Abr. 12 & Noite de S. João para além do muro do meu quintal, [67-49v] \\
\hline 1919 Abr. 12 & Pastor do monte, tão longe de mim com as tuas ovelhas - [67-50v] \\
\hline 1919 Abr. 12 & Tu, místico, vês uma significação em todas as coisas [67-5or] \\
\hline 1919 Abr. 12 & Verdade, mentira; certeza, incerteza... [67-49r] \\
\hline 1919 Abr. 20 & Gozo os campos sem reparar para eles. [67-46v] \\
\hline 1919 Abr. 20 & Gozo os campos sem reparar para eles. [67-47r] \\
\hline 1919 Jun. 20 & Não tenho pressa: não a têm o sol e a lua. [68-13r] \\
\hline 1920 Jul. 19 & Vive, dizes, no presente; [67-61r] \\
\hline 1922 Jun. 4 & Sim, talvez tenham razão. [59-27v] \\
\hline 1922 Jun. 5 & Dizem que em cada coisa uma coisa oculta mora. [59-28] \\
\hline 1922 Maio 7 & Também sei fazer conjecturas... [145] \\
\hline
\end{tabular}




\begin{tabular}{|l|l|}
\hline & \\
\hline 1923 Abr. & Não basta abrir as janelas [67-44r] \\
\hline 1923 Ago. 13 & Ponham na minha sepultura [145] \\
\hline & \\
\hline 1929 Nov. 18 & Eu não sei falar porque estou a sentir. [68-14v] \\
\hline 1929 Nov. 18 & Talvez quem vê bem não sirva para sentir [68-14r] \\
\hline & \\
\hline 1930 Jan. 1 & Aquela senhora tem um piano, [67-26r] \\
\hline 1930 Jun. 13 & Hoje de manhã saí muito cedo, [67-62r] \\
\hline 1930 Jul. 10 & O amor é uma companhia. [67-63r] \\
\hline 1930 Jul. 10 & Mas isto são maneiras de dizer, [67-64r] \\
\hline 1930 Jul. 10 & Passei toda a noite, sem saber dormir, vendo sem nada a figura dela [67-65r] \\
\hline 1930 Jul. 10 & O pastor amoroso perdeu o cajado, [67-64r] \\
\hline 1930 Jul. 10 & Primeiro prenúncio da trovoada de depois de amanhã, [67-66r] \\
\hline 1930 Jul. 23 & Agora que sinto amor [67-67r] \\
\hline
\end{tabular}

Ivo Castro, na apresentação desse importante mapeamento da obra de Caeiro, afirma que:

Está aqui tudo, quase tudo. As primeiras ideias do poema, urgentemente anotadas na esquina de um papel; as suas cópias alinhadas, e depois desalinhadas por chuvas de emendas que se contradizem; as listas de poemas que procuram dar ordem a um ciclo que vai nascendo, e revelam, nas várias renumerações, que essa ordem era tão difícil de encontrar como o som certo de cada verso; as cópias feitas à máquina, que no caso do Guardador se destinaram principalmente a servir de original de imprensa para a publicação em revista, e em vida do poeta, de cerca de metade dos poemas (em outras partes do espólio, os dactiloscritos apresentam-se como o lugar onde da invenção e crescimento do poema); finalmente, certas revisões manuscritas que podem ter sido introduzidas no texto de poemas após a sua publicação nas revistas (Athena e Presença) e que, por esse motivo, superam o texto impresso. Todos estes materiais, que não constituem um bloco no espólio, pelos acasos da inventariação inicial (e definitiva), formam na realidade o dossier genético do Guardador, conjunto de todos os suportes gráficos que participaram no processo de escrita de um texto, organizados segundo a cronologia da sua produção e revelando as relações de transmissão que os ligam. Avulta neste dossier um caderno de 40 folhas de papel almaço, que começou por ser uma cópia limpa do ciclo, já com 49 poemas na ordem final que conhecemos, mas que receberia o maior número das transformações textuais que Pessoa ao longo do tempo introduziria nos seus poemas. O melhor exemplo disto encontra-se na primeira página do poema I, em cujas margens se distribuem, com algum sentido dramático, numerosos estilos caligráficos e instrumentos de escrita que denunciam a frequência das revisitas e revisões. Outros exemplos para que se deve chamar a atenção são oferecidos por transformações mínimas 
introduzidas apenas no remate de certos outros poemas, que têm o efeito de afinar, e por vezes inflectir, o sentido global do texto. (CASTRO, 2006, p. 9).

Ao analisar o trabalho de organização do acervo de Caeiro, nota-se que Fernando Pessoa tinha plena consciência de como seu projeto literário estruturava-se a partir de uma organicidade que pressupunha a revisão, edição e inter-relação entre si mesmo e seus heterônimos. Ainda mais se considerar que o próprio Fernando Pessoa imagina sua existência no conjunto da heteronímia.

As "Notas para a recordação do meu mestre Caeiro" representam, portanto, um valioso estudo/retrato da posição de Alberto Caeiro no projeto poético de Fernando Pessoa, porque redefinem a posição de um poeta que não se encaixa perfeitamente nas propostas modernistas em Portugal. É importante observar que as "Notas" só foram compiladas e ganharam uma unidade em 1997, com o trabalho da professora e pesquisadora Teresa Rita Lopes, que reuniu os vinte e dois fragmentos que iluminam a vida e a obra de Caeiro a partir do ponto de vista de Ricardo Reis, Álvaro de Campos, António Mora, heterônimo pouco conhecido, e Fernando Pessoa, que se torna mais um ser fictício/real na galeria do poeta.

Ao se comparar o quadro acima com a data das poesias de $O$ guardador de rebanhos, observa-se que a construção poética se encerra em 1930. No entanto, em 1931, inicia-se a construção efetiva do poeta Alberto Caeiro com a publicação, assinada por Álvaro de Campos, das “Notas para a recordação do meu mestre Caeiro”. Em carta a João Gaspar Simões, datada de 28 de julho de 1932, Fernando Pessoa escreve sobre suas intenções em publicar uma coletânea com todos os heterônimos. Segundo Pessoa:

O mais provável, aliás, com respeito ao primeiro livro dos heterónimos, é que o faça conter, não só o Caeiro e as Notas do Álvaro de Campos, mas também uns 3 ou 5 livros das Odes do Ricardo Reis. O volume, assim, conterá o essencial para se compreender o início da «escola»: as obras do Mestre e algumas do discípulo direto, incluindo (nas Notas ) alguma coisa já do outro discípulo. Há aqui, ainda, um elemento puramente material que me leva a determinar o volume assim: só com o Caeiro e as Notas, ficaria um livro nem pequeno (como é o Portugal) nem de tamanho normal (30o páginas, pouco mais ou menos), como o Cancioneiro. Com a inserção, lógica afinal, como expliquei, do Ricardo Reis, o volume entra nesta normalidade. (PESSOA, 1982, p. 90). 
Considerado o mestre de todos os heterônimos de Fernando Pessoa, Alberto Caeiro representa o ponto de convergência de todo um projeto literário que busca a essência da poesia num quase apagamento do eu-lírico na representação de um nada que subverte a própria organização da existência humana e seus juízos de valor, suas medidas e valores perante a vida na busca por algo único. Não por acaso todos os movimentos e angústias que motivam os demais heterônimos (e o próprio ortônimo) apaziguam-se na arte poética de Caeiro. Escrever tornara-se algo natural para o poeta que se insere numa zona atemporal, considerando a linguagem como um elemento da natureza. Nesse sentido, na descrição do "Dia triunfal”, 8 de março de 1914, em que Pessoa explica a Adolfo Casais Monteiro a origem de Caeiro e a escrita "num jato" de $O$ guardador de rebanhos, observa-se que esse momento de epifania será o que há de mais refinado na engenharia poética proposta por Fernando Pessoa.

Nesse processo de fazer poesia sem ser poesia, ou seja, a afirmação do mundo sensível pela sua negação, há o intervalo em que Caeiro situa-se na percepção de Álvaro de Campos:

\footnotetext{
Discípulo, como comovidamente sou, do meu mestre Caeiro, sou discípulo com inteligência, e portanto com crítica. Nem ele quereria ser seguido de outra maneira, pois não gostava de animais.

Assim, nunca aceitei aquele critério que há em Caeiro, e que não é das coisas originais que há nele, de que há uma distinção qualquer entre o natural e o artificial. Não há tal distinção, porque ambos são reais. Compreendo a distinção entre os sonhos e a vida, ainda que conceda que um bom metafísico a possa confundir. Mas a distinção entre a árvore e a máquina sempre me pareceu falsa. Parece que a árvore e a máquina são distintas porque a primeira é um produto imediato da natureza, e a segunda um produto mediato aparecido por intermédio da inteligência humana. Mas, na realidade, todo o produto é mediato: a árvore aparece através da semente, a máquina através da inteligência. Tanto a semente como a inteligência são elementos da realidade. $\mathrm{E}$, se dissermos que a árvore surge da semente e a máquina do cérebro teremos reduzido tudo a termos materiais e estabelecido a igualdade de direitos na matéria. (LOPES, 1990, p. 401).
}

Nesse intervalo, o poeta coaduna-se com o tempo, apagando as tensões do passado e a angústia do futuro. Vive um presente contínuo e pulsante que contrasta com os caminhos poéticos propostos por Álvaro de Campos, Ricardo Reis e Bernardo Soares. Ao propor a intuição como método privilegiado, Alberto Caeiro falseia a realidade por meio da visão do mundo natural como medida para a existência humana, existência essa 
quase em sua totalidade falseada pela realidade urbana e artificial. Segundo Ricardo Reis, responsável pela edição dos poemas de Caeiro:

Ignorante da vida e quase ignorante das letras, sem convívio nem cultura, fez Caeiro a sua obra um progresso imperceptível e profundo, como aquele que dirige, através das consciências inconscientes dos homens, o desenvolvimento lógico das civilizações. Foi um progresso de sensações, ou, antes, de maneiras de as ter, e uma evolução íntima de pensamentos derivados de tais sensações progressivas. Por uma intuição sobre-humana, como aquelas que fundam religiões, porém a que não assenta o título de religiosa, por isso que repugna toda a religião e toda a metafísica, este homem descreveu o mundo sem pensar nele, e criou um conceito do universo que não contém uma interpretação. (PESSOA, 1996, p. 329).

Dessa forma, a existência de Caeiro não é "naturalizada” num contexto real, mas ela, contraditoriamente, apaga a artificialidade da poesia, e também da função do poeta como elemento de mediação entre literariedade e existência, ao propor uma metafísica do espaço sem a necessidade de uma linguagem que construa (contraditoriamente) a poesia em si. De certa forma, a poesia de Caeiro chama a atenção para o mundo natural e quando isso acontece as palavras tornam-se desnecessárias. Por isso, o poeta torna-se o "mestre" dos outros heterônimos: a poesia e o poema não precisam reconstruir a realidade ou dar uma explicação metafísica para a existência. Tudo existe. Em resposta à pergunta de Alexander Search, outra criação de Fernando Pessoa, Caeiro deixa pistas sobre sua arte:

— O Sr. Caeiro é um materialista?

— Não, não sou um artista com doutrina nem coisa nenhuma. Sou um homem que um dia, ao abrir a janela, descobriu esta coisa importantíssima: que a natureza existe. Verifiquei que as árvores, os rios, as pedras são coisas que verdadeiramente existem. Nunca ninguém tinha pensado nisto.

Não pretendo ser mais que o maior poeta do mundo.

Fiz a maior descoberta que nenhum antes fez e ao pé da qual todas as outras descobertas são entretimentos de crianças estúpidas. Dei pelo universo. Os gregos, com toda a sua nitidez visual, não fizeram tanto. (PESSOA, 1994, p. 214).

Por outro lado, ao "descobrir a natureza", Caeiro busca o silêncio para compor sua arte poética, ordenando o caos não pela poesia catártica e sonora de Álvaro de Campos ou pelo niilismo entristecido de Ricardo Reis, mas, por outro lado, pelo entendimento do nada que nos rodeia. À primeira vista, esse universo, criado por Pessoa, parece se delinear de forma independente, no entanto cada máscara poética conecta-se 
e, por conseguinte, se completa. Assim sendo, Caeiro precisará ser retratado pelos seus "discípulos" que, por sua vez, geram novas percepções sobre a realidade. Observe-se, por exemplo, o poema XLIV, de O guardador de rebanhos (1994, p. 78):

Acordo de noite subitamente, E o meu relógio ocupa a noite toda.

Não sinto a Natureza lá fora.

O meu quarto é uma coisa escura com paredes vagamente brancas. Lá fora há um sossego como se nada existisse.

Só o relógio prossegue o seu ruído.

E esta pequena coisa de engrenagens que está em cima da minha mesa Abafa toda a existência da terra e do céu...

Quase que me perco a pensar o que isto significa, Mas volto-me, e sinto-me sorrir na noite com os cantos da boca, Porque a única coisa que o meu relógio simboliza ou significa Enchendo com a sua pequenez a noite enorme É a curiosa sensação de encher a noite enorme Com a sua pequenez...

E esta sensação é curiosa porque só para mim é que ele enche a noite Com a sua pequenez...

Escrito em 7 de maio de 1914, o poema XLIV é um exemplo da relação de grandeza na relação eu versus mundo. Ao optar pela luta entre o eu-lírico/relógio e quarto/Natureza, o poeta trava um jogo de equilíbrio que o faz "despertar" para sua consciência. No início do poema, o relógio, e toda sua artificialidade em marcar a passagem das horas, toma conta do quarto a ponto de aprisionar o eu-lírico e estabelecer uma seção com a Natureza.

Torna-se importante colocar as coisas em seu devido lugar e dessa forma esvaziar a noção de noite para um tempo abstrato e, em primeiro plano, devolver o relógio à sua pequenez. O ruído do relógio não causa grandes aborrecimentos porque, ao "acordar", o eu-lírico ressignifica a máquina que "Abafa toda a existência da terra e do céu..." para algo que é apenas acessório. Observa-se no poema um processo de apequenamento do relógio, que ao mesmo tempo que acorda o poeta, desperta-o para sua condição espacial. Há uma transferência de planos em que o temporal dá lugar para o espacial, em que o relógio se torna uma "pequena coisa de engrenagens que está em cima da minha mesa”, causando um abafamento do que é essencial. Ao acordar, o poeta torna-se consciente daquilo que vê e isso lhe dá a objetividade, carregada de lições estoicas, marcada pelo 
sorriso de canto de boca, de que o primordial é saber dimensionar a relação eu/mundo, integrando-se à Natureza e desintegrando o relógio, a parede, a noite.

Segundo a concepção de Blanchot (1987), pode-se alinhar a perspectiva de Caeiro, em relação ao seu espaço, como uma superação ou transfiguração da realidade:

No mundo, as coisas são transformadas em objetos a fim de serem apreendidas, utilizadas, tornadas mais seguras, na firmeza distinta de seus limites e na afirmação de um espaço homogêneo e divisível - mas, no espaço imaginário, transformadas no inapreensível, nos introduz sem reserva num espaço onde nada nos retêm. [...] o espaço interior — traduz as coisasll. Fá-las passar de uma linguagem para outra, da linguagem exterior para uma totalmente interior. $\mathrm{O}$ espaço [que] nos supera e [que] traduz as coisas é, portanto, o transfigurador, o tradutor por excelência. (BLANCHOT, 1987, p. 139).

Ao posicionar o relógio como algo que acorda o poeta e o interrompe de sua conexão com a noite, o eu-lírico volta para a condição em que o tempo não pode ser medido, mas apenas "sentido" como uma forma de existência. No silêncio da noite, o relógio não pode ocupar destaque, deve ser apenas um ruído na "noite enorme”. Assim como a casa, o quarto não pode interromper a relação com a Natureza. De certa forma, o poeta vivencia uma situação de "apagamento" de sua condição, cujo destaque são os versos finais: "E esta sensação é curiosa porque só para mim é que ele enche a noite/ Com a sua pequenez".

Só o poeta possui essa "sensação curiosa”, porque está desperto dentro da noite, porque não se condiciona ao ritmo do relógio, porque não é escravo de uma "máquina de medir a existência”. Dessa forma:

o objeto mostrar-se-ia sem que a menor projeção de subjetividade viesse perturbar a sua percepção absolutamente objetiva. Assim, quando Caeiro escreve expressões como: - não tenho filosofia, tenho sentidos..., ou —os meus pensamentos são todos sensações! É preciso entender —sentidoll e — sensações\| como pertencentes a essa alma exterior, ou seja, a um sujeito que seria totalmente dessubjetivado. (GIL, 2000, p. 31-32).

Essa é a lição que os demais heterônimos buscam em Caeiro: uma capacidade de tornar-se superior ao mundo, de forma objetiva, mas com uma profundidade subjetiva que encontra poesia na complexa simplicidade da existência. Em Álvaro de Campos, Ricardo Reis e Bernardo Soares há sempre uma ponta de amargura, de niilismo, em que 
o mundo nada mais significa. A sabedoria de Caeiro representa algo perdido nos outros heterônimos e por isso sua data de morte, em 1915, é o ano em que se inicia o Modernismo em Portugal. Começa-se um período de ilusões perdidas e por isso Caeiro torna-se a medida do ideal.

Para os outros heterônimos, Caeiro é o equilíbrio que foi perdido pelo homem moderno, não é a poesia que deixou a natureza e foi substituída pela angústia dos labirintos da cidade. É o silêncio que traz a calma, apesar da agitação da alma e do ruído das máquinas.

\section{Referências}

BIBLIOTECA NACIONAL DE PORTUGAL. Espólio Fernando Pessoa: Alberto Caeiro. Lisboa, 2006. Disponível em: https://purl.pt/10oo/1/albertocaeiro/index.html. Acesso em: 30 jan. 2021.

BLANCHOT, Maurice. O espaço literário. Tradução Álvaro Cabral. Rio de Janeiro: Rocco, 1987.

CASTRO, Ivo. A arca de Caeiro. In: BIBLIOTECA NACIONAL DE PORTUGAL. Espólio Fernando Pessoa: Alberto Caeiro. Lisboa, 2006. Disponível em: https://purl.pt/100o/1/alberto-caeiro/apresentacao.html. Acesso em: 30 jan. 2021. GIL, José. Diferença e negação na poesia de Fernando Pessoa. Rio de Janeiro: Relume Dumará, 2000.

LOPES, Teresa Rita. Pessoa por conhecer: textos para um novo mapa. Lisboa: Estampa, 1990.

PESSOA, Fernando. Cartas de Fernando Pessoa a João Gaspar Simões. (Introdução, apêndice e notas do destinatário). $2^{\underline{a}}$ ed. Lisboa: Imprensa Nacional - Casa da Moeda, 1982.

. Páginas íntimas e de auto-interpretação. Edição de Georg Rudolf Lind e Jacinto do Prado Coelho. Lisboa: Edições Ática, 1996. 
Poemas Completos de Alberto Caeiro. Recolha, transcrição e notas de

Teresa Sobral Cunha. Lisboa: Presença, 1994.

SÁ-CARNEIRO, Mário de. Cartas a Fernando Pessoa II. Lisboa: Ática, 1979.

Recebido em 03/03/2021.

Aprovado em 27/04/2021. 